EPiC Series in Education Science
Volume 3, 2020, Pages 81-85
Proceedings of the MIT LINC 2019 Conference

\title{
Effect of Physical Modeling and Computer Animation Implemented with Social Constructivist Instruction on Understanding of Human Reproductive System
}

\author{
Dr. Gonca Esendemir Eskin ${ }^{1}$ and Prof. Dr. Ömer Geban ${ }^{2}$ \\ 1 TED Ankara Collage Private High School, Ankara, Turkey \\ gesendemir@gmail.com \\ 2 Middle East Technical University, Ankara, Turkey
}

\begin{abstract}
Purpose of the study, was to compare effectiveness of the physical modeling and computer animation implemented with social constructivist and traditionally designed instruction on 10th grade students' understanding of human reproductive system, motivation towards learning biology and types of achievement goal orientation. Design of the study was quasi-experimental with 125 students from six intact classes in a private high school in Ankara. Three groups for both experimental and controlled groups were randomly assigned. Students in experimental and control group were exposed to computer animation and physical modeling implemented with social constructivist instruction and traditionally designed biology instruction with respectively.

Results of MANOVA indicated that experimental group showed significantly better acquisition of the scientific concepts and higher motivation towards biology learning than traditionally designed biology instruction. Analysis of ANCOVA showed that students in control group had significantly higher tendency to have performance approach and performance avoidance goals. In contrary there is no significant difference in between two groups related with mastery approach and mastery avoidance goals.

Keywords: Physical Modeling, Computer Animations, Social Constructivism, 2x2 Achievement Goal Orientation, Motivation
\end{abstract}

\section{Introduction}

Human reproduction is a topic that students have difficulties in forming accurate concepts. They have wide range of prior knowledge from scientific and nonscientific sources like their peers [15]. Thus cultural setting play a crucial role while forming concepts and enhances effect of Vygotskian social constructivist approach on the conceptual change of the students. Cultural settings, problem solving, critical thinking, active and reflective use of knowledge, usage of tools, introducing obstacles that disrupt normal problem solving, providing external aids that can be used in different ways and asking problems that exceeds students' knowledge and skills and social organization are the tenets of the approach [3]. Computer animations and physical 
modeling are two ways to support social constructivist approach and have great contributions to create conceptual change. Teaching dynamic processes with computer animations increase achievement of students especially on open- ended questions [14] and physical models that are used as the source analog and act as an instructional tool for understanding a new concept[13], increase intrinsic motivation of students and effect their goal orientation. Motivation is an important factor both for effecting understanding and self-regulation [11]. Leaners' willingness has a crucial role in order to change their conceptions[8] thus creating positive effects on intrinsic behaviour causes better understanding about the concepts. So it is important to measure the effect of physical modeling and computational animation integrated social constructivist instruction (PCSCI) also on increasing students' motivation towards biology learning that was not been searched in the topic of human reproductive system before.

The other main difference of this study is to search for the effect of PCSCI on students' tendency towards different types of achievement goal orientations. Achievement goal orientation, that is also related with motivation [9], can be classified with $2 \times 2$ model as performance avoidance (PAV), performance approach (PA), mastery avoidance (MAV) and mastery approach (MA) goals [12]. Getting better grades, presenting better ability, doing better than others and demonstrating ability to others are main focuses of PA goals. In contrasts PAV goals based on worrying about doing bad and being motivated by the thought of avoiding performing poorly. Both of these performance goals have negative impacts on motivation since main focus of the student is on others rather than the content [10]. MA goals refers to the students who aim to master the task, learn and understand whereas avoiding misunderstanding, not learning and not mastering the task are the main tenets of the students with MAV goals [9].

In the light of this information aim of the research is to figure out the effect of PCSCI compared to traditional instruction on 10th grade students' in terms of creating conceptual understanding about the human reproductive system, motivation towards biology learning and tendency of students towards different types of achievement goal orientation.

\section{Method}

\section{$2.1 \quad$ Subjects}

The subject of the study was consisted of 125 tenth grade students in a private high school. Two instructional methods were randomly delivered to the experimental group and the control group. Number of students in experimental group was 52 and 73 for the control group. Groups were intact groups. The mean age of the students in experimental group and control group are 15 and 15.33 with respectively.

\subsection{Instruments}

Human Reproductive System Conceptual Test (HRSCT)-To assess understanding of chromosomal movements, result of the division, aim of meiosis, anatomy and physiology of the reproductive systems in females and males, sperm and ovum formation, fertilization and hormonal control of the reproductive system in males and females. Student Motivation towards Biology Learning Questionnaire (SMTBL)- To assess intrinsic motivation of the students towards learning biology [1]. Scientific Processing Skills Test (SPST)- It is to measure scientific processing skills of the students with several subsets that focuses on intellectual abilities of students related to identifying variables, identifying and stating hypotheses, operationally defining, designing investigations and graphing and interpreting data [7]. Achievement Goal Questionnaire (AGQ)- 
It has 12 items with the format of seven- scale Likert type [5] and translated into Turkish by the researcher.

\section{Treatment}

This study carried out for four weeks during 2011- 2012 fall semester at a private school in Ankara, Chankaya region. A total of 125 students from six biology classes were the subject of the study. Three teachers were used as instructor. Three of the classes assigned as the experimental group and the other classes as the control group of the study. Experimental group exposed to PCSCI. Whereas control group received traditionally designed biology instruction.

\section{Results}

The results of SPST, pre- SMTBL and pre- HRSCT indicated that there were no significant difference between experimental and control group in terms of, understanding of human reproductive system $(\mathrm{F}=10.381, \mathrm{t}=-0.643, \mathrm{p}>.05)$ and students' intrinsic motivation towards biology learning $(\mathrm{F}=0.004, \mathrm{t}=0.934, \mathrm{p}>.05)$ at the beginning of the treatment. After the treatment MANOVA was carried out, with treatment as the independent variable and post-test scores of the HRSCT and SMTBL as the dependent variables. Statistical analysis indicated that there was a significant mean difference between experimental group and control group with respective to the colligative of dependent variables in the favor of the experimental group ( $\mathrm{F}$ $\left.\left(235.759^{a}\right)=, \mathrm{p}<.05\right)$. Further analysis revealed that there was a significant mean difference between experimental group and controlled group on understanding of human reproductive system conceptions in the favor of the experimental group $(\mathrm{F}=96.508, \mathrm{p}<.05)$. The students in the experimental group demonstrated better performance compared to the control group students. Also the results show that there was a significant mean difference between experimental group and controlled group on students' motivation towards biology learning in the favor of the experimental group $(\mathrm{F}(244.623)=, \mathrm{p}<.05)$. The students in the experimental group demonstrated better motivation level compared to the control group students.

When the value for the difference of the type of achievement goal questionnaire scores across type of treatment was checked by ANCOVA, PA (.002) and PAV (.000) p value is lower than $\alpha$ - level. This indicates that there was a significant mean difference. This significant mean difference was in the favor of the control group for PA goal orientation. Situation can be supported by mean values for experimental and control group were 12.65 and 14.63 with respectively. Moreover same case was observed for the PAV goal orientation as well. Significant difference between the mean values of experimental (10.81) and control group (12.97) was in the favor of the control group. On the other hand for the MA (.263) and MAV goal orientation $(.255) \mathrm{p}$ value was greater than the $\alpha$ - level, therefore there was no significant difference between the scores of the two groups in between type of treatments.

\section{Discussion}

Computer animation and physical modeling served in a positive way to create conceptual change and increase intrinsic motivation due to making students active and comfortable, providing opportunities for discussing issues with their peers in small, studet led and whole class, teacher led discussions. This approach offered students clear and positive goals; variety of activities and tasks at moderate level of difficulty; meaningfulness of content and tasks; and realistic 
level of choice in activities and task formats; instructor who was supportive, facilitative, reassuring and attentive; freedom to work individually or collaboratively in situations that do not encourage competition; active learning environment that was based on hands on activities and collaborative learning.

Even though the method does not have any effect on tendency of students towards having MA or MAV goals, it lowers the tendency towards both of the performance goals. This result revealed that the instructional method created an environment with low focus on ability perceptions and normative comparison, which may still provide a basis for other studies to increase the tendency towards the mastery goals in classrooms and in nonformal educational contexts. Preventing competition was the major concern of PCSCI especially during collaborative learning environment to increase intrinsic motivation of the students[10]. And increase in the intrinsic motivation level of the students was proven by the results of SMTBL questionnaire as well. Therefore results of PA goal are in concordance with the other findings of the study.

As stated before tendency of students towards MA and MAV goal is not effected by the method. This can be related with the duration of the implementation which was four weeks and not long enough [2]. Another explanation can be related with the approach of the school and aim of the students related with university exam. Even if focus on grading was prevented within the classroom, there is still an emphasis on grades from external factors due to university exam which based on normative selection. Thus it was difficult to create an increase in the mastery goals mainly related with the mastery approach ones.

\section{References}

[1] M. Başer. The contribution of learning motivation, reasoning ability and learning orientation to ninth grade international baccalaureate and national program students' understanding of mitosis and meiosis. Master's thesis, Middle East Technical University, Ankara, Turkey, 2007.

[2] R. Cuevas, O. Contreras, and T. Garcia-Calvo. Effects of an experimental program to improve the motivation in physical education of spanish students. Procedia-Social and Behavioral Sciences, 47:734-738, 2012.

[3] M.P. Driscoll. Psychology of Learning for Instruction. Pearson, Toronto, ON, 2005.

[4] A.J. Elliot. Approach and avoidance motivation and achievement goals. Educational Psychologist, 34:169-189, 1999.

[5] S.J. Finney, S.L. Pieper, and K.E. Barron. Examining the psychometric properties of the achievement goal questionnaire in a general academic context. Educational and Psychological Measurement, 64:365-382, 2004.

[6] F. Flores. Representation of the cell and its processes in high school students: an integrated view. International Journal of Science Education, 25(2):269-286, 2003.

[7] O. Geban, P. Askar, and I. Ozkan. Effects of computer stimulations and problem solving approaches on high school students. Journal of Educational Research, 86:5-10, 1992.

[8] M.J. Leonard, S.T. Kalinowski, and T.C. Andrews. Misconceptions yesterday, today, and tomorrow. CBE: Life Sciences Education, 13:179-186, 2014.

[9] C. Nien and J.L. Duda. Antecedents and consequences of approach and avoidance achievement goals: A test of gender invariance. Psychology of Sport and Exercise, 9(3):352-372, 2008.

[10] D. Palmer. A motivational view of constructivist - informed teaching. Internal Journal of Science Education, 27:1853- 1881, 2005.

[11] P.R. Pintrich. The role of motivation in promoting and sustaining self-regulated learning. International Journal of Educational Research, 31:459- 470, 1999.

[12] P.R. Pintrich. Handbook of self-regulation. Academic Press, NY, USA, 2000. 
[13] Y. Rotbain, G. Marbach-Ad, and R. Stavy. Effects of bead and illustrations models on high school studens' achievement in molecular genetics. Journal of Research in Science Teaching, 43:500-529, 2006.

[14] Y. Rotbain, G. Marbach-Ad, and R. Stavy. Using a computer animation to teach high school molecular biology. Journal of Science Education and Technology, 17:49-58, 2007.

[15] L. Veiga, F. Teixeira, I. Martins, and A. Meliço-Silvestre. Sexuality and human reproduction: a study of scientific knowledge, behaviors and beliefs of portuguese future elementary school teachers. Sex Education, 6(1):17-29, 2006. 